\title{
Heats of Hydrolysis of Phenyl Acetate and Phenyl Thiolacetate
}

I N G E A R W A D S O

Thermochemistry Laboratory *, University of Lund, Sweden

\begin{abstract}
The heats of hydrolysis of phenyl acetate and phenyl thiolacetate have been determined calorimetrically at $25^{\circ} \mathrm{C}$. For the idealized, isothermal hydrolysis reactions

and

$$
\operatorname{PhOAc}(\mathrm{l})+\mathrm{H}_{2} \mathrm{O}(\mathrm{l}) \rightarrow \mathrm{PhOH}(\mathrm{s})+\mathrm{HOAc}(\mathrm{l})
$$$$
\operatorname{PhSAc}(\mathrm{l})+\mathrm{H}_{\mathbf{2}} \mathrm{O}(\mathrm{l}) \rightarrow \mathrm{PhSH}(\mathrm{l})+\mathrm{HOAc}(\mathrm{l})
$$

the enthalpy changes were found to be $-6.86 \pm 0.06$ and $-2.97 \pm$ $0.08 \mathrm{kcal} / \mathrm{mole}$, respectively.

Heat and free energy changes in transacylation from phenyl thiolacetate to thiols have been briefly discussed.
\end{abstract}

$T^{\mathrm{s}}$ The simple phenyl thiolacetate as well as aminoacyl derivatives of thiophenol have been used extensively during recent years, as acylating agents towards thiols and amines in peptide chemistry. Also O-phenylesters, preferably nitro-substituted, have been proved to be useful in this connection ${ }^{1}$.

Phenol and thiophenol derivatives of aminoacids and peptides can be looked upon as "active forms" of the corresponding acids. They can be condensed, under conditions that are possible in the cell, with another aminoacid or peptide, by which reaction a peptide bond is formed:

$\mathrm{X}=\mathrm{O}, \mathrm{s}$.

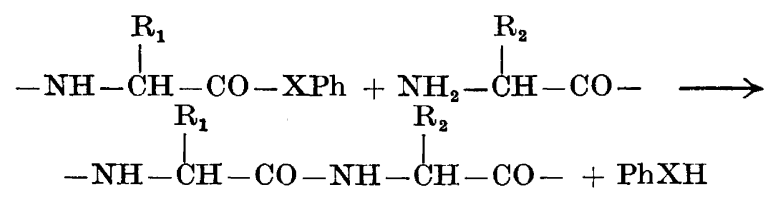

The acylated phenols have been described as "energy-rich" i.e. their hydrolysis reactions have been supposed to proceed under release of a large amount

* Sponsored by The Swedish Natural Science Research Council and by The Swedish Technical Research Council. 
Table 1. Heats of hydrolysis of phenyl acetate and phenylthiol acetate.

\begin{tabular}{lcccc} 
Substance & mmoles & $\varepsilon$ & $10^{4} \times \log R_{\mathrm{i}} / R_{\mathrm{f}}$ & $-\Delta H, \mathrm{kccl} / \mathrm{mole}$ \\
PhOAc & 3.536 & 7752 & 95.48 & 20.93 \\
& 3.335 & 7750 & 89.84 & 20.88 \\
& 3.303 & 7750 & 89.30 & 20.95 \\
& 3.228 & 7750 & 87.08 & 20.91 \\
\cline { 3 - 4 } PhSAc & & & & Mean $20.92 \pm 0.02$ \\
& 3.397 & 7724 & 94.29 & 21.44 \\
& 3.267 & 7723 & 90.79 & 21.46 \\
& 3.228 & 7723 & 89.85 & 21.54 \\
\hline & 3.172 & 7722 & 88.49 & Mean 21.49 \pm 0.03
\end{tabular}

of free energy. As in a simple hydrolysis reaction the entropy term is small, the enthalpy change is of the same order as the free energy change. Therefore, it seemed to be of interest to determine the heats of hydrolysis of the acetic acid esters of the simple phenol and thiophenol, thereby also supplementing the recently performed measurements on alkyl acetates ${ }^{2}$ and alkyl thiolacetates $^{3}$.

\section{EXPERIMENTAL}

Materials." Phenyl acetate was prepared from phenol and acetic anhydride 4. The crude product was purified by distillation at different pressures in a 10-plate column, followed by fractional freezing out. The product reacted neutral. The equivalent weight, as determined by potentiometric titration of the acetic acid formed by hydrolysis, coincided with the theoretical value within the limits of experimental error. $d_{4}^{25}=1.0740$, $n_{\mathrm{D}}^{25}=1.5010$.

Phenyl thiolacetate was prepared from benzene thiol and acetyl chloride ${ }^{5}$. The ester was purified by distillation, until the equivalent weight, as determined by iodometric titration of thethiol formed by alkaline hydrolysis ${ }^{2}$, indicated $100.0 \%$ purity. The product rescted neutral and did not consume any iodine. $d_{4}{ }^{25}=1.1164, n_{\mathrm{D}}{ }^{25}=1.5690$.

Phenol of purum grade was purified by fractional freezing out until a colourless substance with a melting point at $41.0^{\circ} \mathrm{C}$ was obtained.

Benzene thiol was distilled until iodometric titration in water-ethanol gave an equivalent weight indicating $100.0 \%$ purity.

Acetic acid was purified by fractional freezing out 4 times. Titration values proved the substance to be pure within the limits of experimental error.

Apparatus. The reactions were carried out in a metal "isothermal" calorimeter which has been described in detail elsewhere (Type D in Ref. $\left.{ }^{6}\right)$.

Calibration. The heat equivalent of the calorimeter, including its content, was determined electrically by passing a known current for a given time $(240 \mathrm{sec})$ through the heating element. The calibrations were performed on the system after hydrolysis had taken place. The result of each calibration experiment was adjusted to give the heat equivalent of $a$ "standard system", $\varepsilon^{\circ}$, in which the calorimetric liquid contained the hydrolysis products from a certain amount of ester $(450 \mathrm{mg})$. The actual heat equivalent values, $\varepsilon$, were obtained from $\varepsilon^{\circ}$ by applying small corrections for the variations in the amount of substance used.

Calorimetric procedure. In order to obtain a rapid reaction, the hydrolyses were performed in strong $(0.8 \mathrm{~N})$ sodium hydroxide, water-ethanol $(2: 3)$ solution. The calorimeter was charged with $100 \mathrm{ml}$ of this solution. After equilibration, the reaction was started by breaking the sealed glass ampoule containing the ester. The thiol formed from phenyl thiolacetate was to a certain extent oxidised in the alkaline medium, as was the case with 
Table 2. Heat of solution measurements.

\begin{tabular}{|c|c|c|c|c|c|}
\hline Substance| & mmoles & $\varepsilon$ & $10^{4} \times \log R_{\mathrm{i}} / R_{\mathrm{f}}$ & \multicolumn{2}{|c|}{$-\Delta H, \mathrm{kcal} / \mathrm{mole}$} \\
\hline \multirow[t]{2}{*}{$\mathrm{PhOH}$} & $\begin{array}{l}3.801 \\
3360 \\
3.356 \\
3521\end{array}$ & $\begin{array}{ll}7 & 746 \\
7 & 745 \\
7 & 745 \\
7 & 745\end{array}$ & $\begin{array}{l}12.86 \\
11.35 \\
11.55 \\
11.98\end{array}$ & & $\begin{array}{l}2.62 \\
2.62 \\
2.67 \\
2.64 \\
\end{array}$ \\
\hline & & & & Mean & $2.64 \pm 0.02$ \\
\hline \multirow[t]{2}{*}{ PhSH } & $\begin{array}{l}3.433 \\
3.115 \\
3.507 \\
3.409\end{array}$ & $\begin{array}{ll}7 & 718 \\
7 & 716 \\
7 & 719 \\
7 & 718\end{array}$ & $\begin{array}{l}31.42 \\
28.74 \\
32.19 \\
31.51\end{array}$ & & $\begin{array}{l}7.06 \\
7.12 \\
7.08 \\
7.13 \\
\end{array}$ \\
\hline & & & & Mean & $7.10 \pm 0.04$ \\
\hline \multirow[t]{2}{*}{ HOAc } & $\begin{array}{l}3.809 \\
3.499 \\
3.421 \\
3.392 \\
3.684\end{array}$ & $\begin{array}{ll}7 & 741 \\
7 & 740 \\
7 & 740 \\
7 & 736 \\
7 & 737\end{array}$ & $\begin{array}{l}57.23 \\
52.36 \\
51.43 \\
50.98 \\
55.35\end{array}$ & & $\begin{array}{l}11.63 \\
11.58 \\
11.64 \\
11.63 * \\
11.63 *\end{array}$ \\
\hline & & & & Mean & $11.62 \pm 0.02$ \\
\hline \multirow[t]{2}{*}{$\mathrm{H}_{2} \mathrm{O}$} & $\begin{array}{l}3.470 \\
4.087\end{array}$ & $\begin{array}{l}7738 \\
7738\end{array}$ & $\begin{array}{l}0.92 \\
1.02\end{array}$ & & $\begin{array}{l}0.21 \\
0.19 \\
\end{array}$ \\
\hline & & & & Mean & $0.20 \pm 0.01$ \\
\hline
\end{tabular}

aliphatic thiols $:$ However, it was found that the autoxidation of benzene thiol was much slower than that observed for aliphatic thiols. In order to cancel the heat effect of autoxidation, the same technique as given in Ref. ${ }^{2}$ had to be used. Thus the experiments on phenyl thiolacetate and benzene thiol were performed in a solution in which a small amount $(0.5 \mathrm{ml})$ of benzene thiol has been substituted for the calorimetric liquid. As seen from the results given in Table 2, presence of thiol did not significantly change the heat of solution value of acetic acid.

In every case the reaction period was 8 minutes or less. The initial and final thermistor resistances ( $R_{\mathrm{i}}$ and $R_{\mathrm{f}}$, respectively) were obtained graphically.

Corrections to standard states. The ideal isothermal hydrolysis reaction $\mathrm{V}$ is obtained from eqns. I and IV, which correspond to the reactions taking place under actual experimental conditions.

\begin{tabular}{|c|c|c|c|}
\hline $\begin{array}{l}\text { I } \\
\text { III } \\
\text { IV }\end{array}$ & $\begin{array}{l}\operatorname{PhXAc}(1)+ \\
\operatorname{PhXH}(\mathrm{s} / 1) \\
\mathrm{HOAc}(1) \\
\mathrm{H}_{2} \mathrm{O}(1)\end{array}$ & 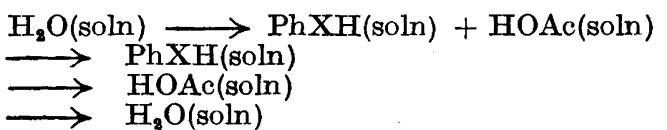 & $\begin{array}{ll}\Delta & \mathrm{H}_{1} \\
\Delta & \mathrm{H}_{2} \\
\Delta & \mathrm{H}_{8} \\
\Delta & \mathrm{H}_{4}\end{array}$ \\
\hline $\mathrm{V}$ & $\begin{array}{l}\mathrm{RXAc}(\mathrm{l})+ \\
\Delta H^{0}=\Delta\end{array}$ & $\begin{array}{l}{ }_{2} \mathrm{O}(\mathrm{l}) \longrightarrow \mathrm{RXH}_{2}-\Delta H_{3}+\Delta H_{4}+\mathrm{HOAc}(\mathrm{l}) \\
-\Delta H_{2}\end{array}$ & $\Delta \mathrm{H}^{0}$ \\
\hline
\end{tabular}

Units of measurement. The results of the calorimetric experiments are expressed in terms of the defined calorie, equal to 4.1840 abs. joules, and refer to the isothermal process at $25^{\circ}$, and to the true mass. The molecular weights were computed from the 1951 table of international atomic weights ?.

* PhSH present. $99.79 \mathrm{ml}$ of calorimetric liquid. 


\section{RESULTS}

From four calibration experiments on the system (containing $99.79 \mathrm{ml}$ of calorimetric liquid) where no benzene thiol was added, the standard heat equivalent, $\varepsilon^{\circ}$, was found to be $7750 \pm 8 * \mathrm{cal} /$ unit of $\log R_{\mathrm{i}} / R_{\mathrm{f}}$. From four calibration experiments on the system $(99.40 \mathrm{ml}$ of calorimetric liquid) where benzene thiol was present, the $\varepsilon^{0}$-value was found to be $7721 \pm 7 \mathrm{cal} /$ unit of $\log R_{\mathrm{i}} / R_{\mathrm{f}}$.

In the tables the following symbols have been used:

$\log R_{\mathrm{i}} / R_{\mathrm{f}}$ the expression proportional to the temperature change;

$R_{\mathrm{i}}$ and $R_{\mathrm{f}}$ are the corrected thermistor resistance values at the start and the end, respectively, of the main period;

$\boldsymbol{\varepsilon}$

the heat equivalent of the actual system in calories per unit of $\log R_{\mathrm{i}} / R_{\mathrm{f}}$.

\section{Table 3.}

Substance

PhOAc

PhSAc

$$
-\triangle H_{1}
$$

21.49

$\begin{array}{cc}-\Delta H_{2} & -\Delta H_{3} \\ 2.64 & 11.62 \\ 7.10 & 11.62\end{array}$

$$
\begin{gathered}
-\Delta H_{4} \\
0.20 \\
0.20
\end{gathered}
$$

$-\triangle H^{0}$

$6.86 \pm 0.04$

$2.97 \pm 0.06$

Table 3 contains a summary of the obtained data and the heat of hydrolysis of the idealized reaction $\mathrm{V}$. The uncertainties given in the table do not include possible systematic errors. As the accuracy of the titrations, by which the purity of the esters and actic acid was tested, cannot be considered to be better than $\pm 0.2 \%$, the true uncertainties are somewhat greater. Taking this into consideration, the standard heats of hydrolysis for phenyl acetate and phenyl thiolacetate will be $-6.86 \pm 0.06$ and $-2.97 \pm 0.08 \mathrm{kcal} / \mathrm{mole}$, respectively.

\section{DISCUSSION}

In a forthcoming paper, heats of hydrolysis data for some $\mathrm{O}, \mathrm{S}$ and $\mathrm{N}$ acetyl compounds will be discussed more generally. Here, the derived heat of hydrolysis of phenyl thiolacetate will be compared with the corresponding data for some alkyl thiolacetates (Table 4).

Table 4. $\Delta H^{0}$ for the hydrolysis of some alkyl thiolacetates ${ }^{2}$ and phenyl thiolacetate.

$\begin{array}{lcccccc}\text { Substance } & \text { EtSAc } & n \text {-PrSAc } & n \text {-BuSAc } & i \text {-PrSAc } & t \text {-BuSAc } & \text { PhSAc } \\ \Delta H^{\circ}, \mathrm{kcal} / \mathrm{mole} & -0.95 & -0.93 & -1.09 & -1.39 & -3.00 & -2.97\end{array}$

The enthalpy change for a transacylation reaction $\mathrm{R}_{1} \mathrm{SAc}+\mathrm{R}_{2} \mathrm{SH} \rightarrow$ $\mathrm{R}_{1} \mathrm{SH}+\mathrm{R}_{2} \mathrm{SAc}$ is equal to the difference of the heat of hydrolysis of the two thiolesters. If all reaction participants are liquids, the entropy change must be very small, considering the symmetric nature of the reaction. The same applies to the substances in solution, provided the interactions between the

* All uncertainties given are the average deviation of the mean. 
medium and the reactants, and the reaction products, respectively, are of the same magnitude. Therefore, the standard free energy change for the reaction, should in this case be very nearly the same as the standard enthalpy change. Thus, when acetylating alkyl thiols by phenyl thiolacetate, the reaction seems to be accompanied by a standard free energy change of ca $2 \mathrm{kcal} / \mathrm{mole}$ or less. Therefore, from an energetic point of view, phenyl thiolacetate cannot be considered as an effective acetylating agent towards alkyl thiols. This conclusion is confirmed, e.g., by the experiments carried out by Wieland and Bokelmann ${ }^{8}$, who had to use phenyl thiolacetate in a tenfold excess in order to get glutathione "completely" S-acetylated in an acid water methanol solution.

Acknowledgements. This work has been supported by a grant from University of Lund.

\section{REFERENCES}

1. Wieland, Th. and Heinke, B. Ann. 615 (1958) 184.

2. Wadsö, I. Acta Chem. Scand. 11 (1957) 1745.

3. Wadsö, I. Acta Chem. Scand. 12 (1958) 630.

4. Vogel, A. I. Practical Organic Chemictry. Longmans, Green and Co. London 1948.

5. Michlar, W. Ann. 176 (1875) 177.

6. Sunner, S. and Wadsö, I. Acta Chem. Scand. 13 (1959) 97.

7. Wichers, E. J. Am. Chem. Soc. 74 (1952) 2447.

8. Wieland, Th. and Bokelmann, E. Angew. Chem. 64 (1952) 59.

Received November 12, 1959. 